\title{
Coronary angiography after cardiac arrest without ST-segment elevation (COACT)
}

\author{
Andrew Guy $\oplus^{\circ}, \mathrm{MD}^{*}$; Riley Golby, MD*; Rob Stenstrom, MD, PhD*
}

\begin{abstract}
Link: https://www.nejm.org/doi/full/10.1056/ NEJMoa1816897

Full Citation: Lemkes JS, Janssens GN, van der Hoeven NW, et al. Coronary angiography after cardiac arrest without ST-segment elevation. N Engl J Med 2019;380(15):1397-407.
\end{abstract}

Article Type: Therapy.

Ratings: Methods $-5 / 5$ Usefulness $-4 / 5$

\section{INTRODUCTION}

\section{Background}

Early coronary angiography has been shown to improve survival after cardiac arrest in patients with ST-segment elevation on electrocardiogram (ECG). ${ }^{1}$ However, it is unknown whether there is benefit to early angiography in postarrest patients without ST-segment elevation. ${ }^{2}$

\section{Objectives}

Guy and colleagues sought to compare early versus delayed coronary angiography in patients after cardiac arrest without ST-segment elevation on ECG. ${ }^{2}$

\section{METHODS}

\section{Design}

This study was a multi-center, open-label, randomized controlled trial.

\section{Setting}

Nineteen tertiary care hospitals in the Netherlands between 2015-2018.

\section{Subjects}

Patients with out-of-hospital cardiac arrest and initial shockable rhythm found to be unconscious (Glasgow Coma Scale score < 8) after return of spontaneous circulation without ST-elevation on ECG.

\section{Intervention}

Immediate coronary angiography within 2 hours of randomization compared with delayed angiography after neurologic recovery.

\section{Outcomes}

Primary outcome was overall survival at 90 days. Secondary endpoints included various clinical outcomes during the subsequent hospital admission, along with rates of neurological disability at intensive care unit discharge and at 90 days.

\section{RESULTS}

A total of 552 patients were enrolled in the trial, with 273 randomized to immediate and 265 to delayed coronary angiography groups. Baseline patient characteristics were balanced between the two groups. Treatment with angiography was received by $97 \%$ of the immediate group and $65 \%$ of the delayed group, with percutaneous coronary intervention (PCI) performed in 33\% and $24.2 \%$, respectively. The rate of unstable coronary lesions on angiography was $14.8 \%$, and the rate of acute thrombotic occlusion was $5.0 \%$. Median time from randomization to treatment was 0.8 hours in the immediate group and 120 hours in the delayed group. Both groups received standard critical care including targeted temperature management in $90 \%$ of patients. The

From the * Department of Emergency Medicine, University of British Columbia, Vancouver, BC.

(C) Canadian Association of Emergency Physicians 
primary outcome of survival at 90 days was $64.5 \%$ in the immediate angiography group compared with $67.2 \%$ in the delayed angiography group (odds ratio, $0.89 ; 95 \%$ confidence interval, $0.62-1.27 ; p=0.51)$. No differences were found in any of the secondary outcomes. In both groups, three times as many patients died of neurologic causes as from cardiac causes.

\section{APPRAISAL}

\section{Strengths}

- Clear, sensible, and important question

- Rigorous methodology with careful randomization

- Internally valid

- Standardized approach to coronary intervention

- High rate of follow-up

- Minimal cross-over between arms and intention to treat analysis

- Comparable groups at baseline

- Multi-center trial

- Cardiac arrest critical care was delivered in a developed nation, likely with similar management to North American practice

\section{Limitations}

- Limited generalizability given low coronary disease burden of the studied population

- Prior literature revealed rates of acute occlusive lesions between 25 and $58 \%$ in patients postcardiac arrest without ST-elevation on ECG, ${ }^{2}$ whereas this study population was found to be only $5 \%$. This low rate of culprit lesions reduces the number of patients who could potentially benefit from early PCI, further evidenced by the study PCI rate of only $30 \%$ after angiography.

- Performed in one country in Europe

- Did not examine neurologically intact survival as a primary outcome, although it was examined as a secondary outcome

- Blinding was not possible due to nature of the intervention

- Differences between time to targeted temperature management may have been a confounding factor

\section{CONTEXT}

This is the first randomized controlled trial comparing immediate versus delayed coronary angiography after cardiac arrest without ST-elevation. The results will be valuable in determining the urgency of angiography after cardiac arrest. Currently, there are two additional randomized controlled trials ongoing within a North American context to solidify or refute these results and expand on the generalizability of this research. ${ }^{3}$

\section{BOTTOM LINE}

This study showed no difference between these two strategies with respect to the primary outcome of 90-day survival. There are several limitations related to the external validity of these results, and additional trials to confirm or refute these results are ongoing. Emergency physicians should be aware of the results of this study to facilitate informed conversations with consultants. Clinical judgement should still be used until more generalizable evidence is available and emergency physicians should advocate for their patients to receive timely and appropriate care.

Key words: Cardiac arrest, coronary angiography, percutaneous coronary intervention

Competing interests: None declared.

\section{REFERENCES}

1. Ibanez B, James S, Agewall S, et al. 2017 ESC Guidelines for the management of acute myocardial infarction in patients presenting with ST-segment elevation: the Task Force for the management of acute myocardial infarction in patients presenting with ST-segment elevation of the European Society of Cardiology (ESC). Eur Heart 7 2018;39:119-77.

2. Kern KB, Lotun K, Patel N, et al. Outcomes of comatose cardiac arrest survivors with and without ST-segment elevation myocardial infarction: importance of coronary angiography. FACC Cardiovasc Interv 2015;8:1031-40.

3. ClinicalTrials.gov [Internet]. Bethesda (MD): National Library of Medicine (US). Identifier NCT03119571. ACCESS to the Cardiac Cath Lab in Patients Without STEMI Resuscitated From Out-of-hospital VT/VF Cardiac Arrest; April 18, 2017 [cited August 8, 2019]. Available at: https://clinicaltrials.gov/ct2/show/NCT03119571 (accessed October 16, 2019). 